\title{
The Endogenous Metabolism of Euglena gracilis
}

\author{
BY W. F. DANFORTH AND B. W. WILSON \\ Department of Biology, Illinois Institute of Technology, Chicago, Illinois, U.S.A., \\ and Department of Zoology, University of California, Los Angeles, \\ California, U.S.A.
}

(Received 18 July 1960)

\section{SUMMARY}

The endogenous respiratory rate of non-photosynthetic Euglena gracilis var. bacillaris is remarkably constant under varied conditions of growth and incubation. After $60-90 \mathrm{~min}$. of slightly more rapid respiration, the endogenous oxygen uptake averages about $6.5 \mu \mathrm{l} . \mathrm{O}_{2} /$ million cells/ hr., and this rate can be maintained for at least $26 \mathrm{hr}$. The respiratory quotient of the endogenous metabolism is 1.0. Fluoroacetate inhibits endogenous oxygen consumption about $70 \%$. A variety of evidence suggests that the polysaccharide paramylum is the major endogenous substrate.

Tracer experiments indicate that the endogenous metabolism continues during the oxidation of exogenous substrates, but that the assimilated substrate mixes with, and dilutes the endogenous reserves. The time-course of this dilution process indicates that the most recently assimilated reserves are the first to be oxidized.

\section{INTRODUCTION}

In the absence of exogenous substrate, cells of Euglena gracilis var. bacillaris (non-photosynthetic strain) have a respiratory rate roughly one-quarter that on a substrate such as acetate or ethanol. Previous manometric experiments indicated that this endogenous respiration continues unabated during the metabolism of exogenous acetate (Wilson \& Danforth, 1958). The experiments described here were designed to provide further information concerning this endogenous metabolism and its relation to the metabolism of exogenous substrates.

\section{METHODS}

Experiments were done on the same non-photosynthetic strain of Euglena gracilis var. bacillaris used in previous studies (Danforth, 1953; Danforth \& Wilson, 1957; Wilson \& Danforth, 1958). Cells were grown at c. $20^{\circ}$ in a medium composed of (w/v) Bacto-Tryptone (Difco), $0.25 \%$; with $\mathrm{Na}$ acetate $3 \mathrm{H}_{2} \mathrm{O}, 0.3 \%$ (w/v) at pH 7.3; or ethanol, $0.3 \%(\mathrm{v} / \mathrm{v})$ at $\mathrm{pH} 3.5$ as carbon sources. Several experiments on the rate of endogenous oxygen consumption were performed on cells grown at 24-25 in the chemically defined medium of Cramer \& Myers (1952), with acetate, $0.5 \%$ $(\mathrm{w} / \mathrm{v})$; or succinate, $0.5 \%(\mathrm{w} / \mathrm{v})$ at $\mathrm{pH} 7.0$ or fumarate, $0.5 \%(\mathrm{w} / \mathrm{v})$; malate, $0.5 \%(\mathrm{w} / \mathrm{v})$; or $\alpha$-ketoglutarate, $0.5 \%(\mathrm{w} / \mathrm{v})$ at $\mathrm{pH} 5.0$ as sole carbon sources. Cells were harvested and washed by centrifugation before experimental use. These 
procedures have been described in more detail in the previous publications cited above.

'Partially-labelled' Euglena was prepared by incubating the cells for 10-20 min. in $0.01 \mathrm{M}$-phosphate buffer $\left(\mathrm{pH} \mathrm{7 \cdot 0}\right.$ ) containing $5 \cdot 0-6 \cdot 4 \mu$ mole of $\mathrm{Na}$ acetate-2- ${ }^{14} \mathrm{C}$. 'Fully-labelled' cells were prepared by inoculating $1 \mathrm{ml}$. of Euglena culture into $300 \mathrm{ml}$. growth medium containing acetate-2-14 $\mathrm{C}$. Cells were harvested after 8 days of growth in this medium. The labelled cells were dispersed into experimental media in Warburg flasks or $50 \mathrm{ml}$. Erlenmeyer flasks equipped with centre wells. Each centre well received $0.5 \mathrm{ml}$. (Warburg) or $0.1 \mathrm{ml}$. (Erlenmeyer) of $0.1 \mathrm{M}-\mathrm{NaOH}$. Flasks were stoppered and shaken at $120 \mathrm{cyc}$./min. Experiments were performed at 21-26. At approximately hourly intervals, the $\mathrm{NaOH}$ was withdrawn from the centre wells and the wells rinsed and refilled with the same volume of fresh $\mathrm{NaOH}$. The entire withdrawal, rinsing, and refilling took less than a minute, so loss of $\mathrm{CO}_{2}$ during this process was probably less than $2 \%$ of the measured values. Samples of the $\mathrm{NaOH}$ withdrawn were spread uniformly on planchets with the addition of ethanol and were dried under an infra-red lamp. Radioactivity was counted with a thin-window Geiger tube for a period of time sufficient to give a total count of 1000 or more. Background was counted to the same degree of accuracy, and was subtracted from all counts. No correction was made for self-absorption, since preliminary experiments had indicated that differences in self-absorption between samples were negligible.

In some experiments samples of labelled Euglena were killed in known volumes of alkaline ethanol $(0.01 \mathrm{M}-\mathrm{NaOH}$ in $95 \%(\mathrm{v} / \mathrm{v})$ ethanol), at the beginning and the end of the experiment. Known volumes of these samples were dried on planchets, and counted to determine the radioactivity of the cells.

Under the experimental conditions described above, there was a certain amount of retention of $\mathrm{CO}_{2}$ in the incubation medium. To determine whether the incomplete recovery of $\mathrm{CO}_{2}$ caused any serious error in the results, a number of experiments were performed by a method designed to eliminate the effect of $\mathrm{CO}_{2}$ retention. In these experiments, samples were removed from the incubation flasks at intervals and centrifuged. The cells were washed and resuspended in fresh medium, and these new suspensions transferred to Warburg flasks whose centre wells contained $0 \cdot 4 . \mathbf{~ m l}$. of $0.1 \mathrm{M}-\mathrm{NaOH}$ and whose sidearms contained $0.5 \mathrm{ml}$. of $0.1 \mathrm{M}-\mathrm{H}_{2} \mathrm{SO}_{4}$. After incubation for the desired period, the sidearms were tipped, killing the Euglena and acidifying the medium. The flasks were shaken for another hour to complete the diffusion of $\mathrm{CO}_{2}$ to the centre well, and the centre well contents were sampled and counted as before. The experiments shown in Figs. 3 and 6 were done by this method. In every case the results of such experiments were similar to those using the simpler method described above.

Respiration was measured by standard Warburg techniques, at $26^{\circ}$, in a gas phase of air. The respiratory quotient was determined by the acid end-point method described in a previous report (Wilson \& Danforth, 1958). Respiration of cells grown in Cramer-Myers medium was measured in the same medium minus carbon source. Tris (2-amino-2" hydroxymethylpropane-1:3-diol) buffer + phosphate (tris + phosphate) or phosphate alone were used as buffers for other respiratory experiments.

To determine the volume of Euglena cells, measured portions of a heavy suspen- 
sion of Euglena were centrifuged in Hopkins vaccine tubes until the cells were packed in the narrow graduated portions of the tubes. Centrifugation was continued until a pellet of constant volume was achieved. Because the plasticity of the Euglena pellicle permits tight packing, the volume of extracellular water in such pellets was probably small. The number of cells was determined by haemocytometer counts on samples of the same suspension.

Na acetate-2-14 C was obtained from the Volk Radiochemical Company, Chicago, Illinois; $\mathrm{Na}$ fluoroacetate (Compound 1080, $10 \%$ inert material) was the gift of Mr Tull C. Allen, Tull Chemical Company, Inc., Oxford, Alabama, U.S.A.

\section{RESULTS}

General characteristics of the endogenous metabolism. As was noted by Von Dach (1942) in the closely related Astasia, Euglena cells often have a slightly higher rate of endogenous metabolism during the first hour or two after harvesting than at later periods. When cells grown in Cramer-Myers medium with acetate, succinate, fumarate, malate, or $\alpha$-ketoglutarate were incubated at $\mathrm{pH} 5 \cdot 0,5 \cdot 5$ or $7 \cdot 0$, eighteen experiments yielded an average initial endogenous respiration rate of $8 \cdot 2 \pm 1 \cdot 2$ (av. dev.) $\mu \mathrm{l} . \mathrm{O}_{2} /$ million cells $/ \mathrm{hr}$. After this initial period of rapid respiration, the rate decreases to a constant level, 6.5 $\pm 1 \cdot 0 \mu \mathrm{l} . \mathrm{O}_{2} /$ million cells $/ \mathrm{hr}$. in the same series of experiments. The same change has been noted in cells grown on Tryptone media with acetate or ethanol as growth substrates, and incubated in tris-phosphate buffer. The endogenous respiratory rate was independent of the growth substrate, the presence or absence of a nitrogen source in the incubation medium, the $\mathrm{pH}$ of incubation, and the other differences in incubation media described under 'Methods'.

The later, steady rate of endogenous respiration is maintained for long periods of time. In the longest experiment performed, the rate of endogenous metabolism during the 24th to 26 th hour was $93 \%$ of that during the 3rd and 4th hour. Assuming that the rate of $\mathrm{O}_{2}$ consumption in this experiment equalled the average rate of 6.5 $\mu \mathrm{l}$./million cells $/ \mathrm{hr}$. (unfortunately the cell count sample in this experiment was lost), the total oxygen consumption during the entire experiment was $7 \cdot 3 \mu$ mole/ million cells, equivalent to the complete oxidation of $3.6 \mu$ mole of acetate or $1.2 \mu$ mole hexose/million cells. Since the respiratory rate was still appreciable at the end of the experiment, it is clear that these are minimum estimates of the endogenous reserves of Euglena cells.

Effect of fluoroacetate on endogenous metabolism. It would be of some interest to determine the pathways and intermediates involved in the endogenous metabolism of Euglena, particularly in view of the metabolic scheme presented in the discussion, which assumes a minimum of interaction between the endogenous metabolism and that of exogenous substrates. Some few data bearing on this problem have been obtained.

One source of such data are experiments involving the inhibitor, fluoroacetate. In higher animals, this substance has been shown to be incorporated, by way of the 'condensing enzyme', into fluorocitrate, which inhibits the enzyme aconitase and thus blocks citrate metabolism (Peters, 1952, 1957). Danforth (1952) found that fluoroacetate inhibited acetate oxidation by Euglena, but was unable to demonstrate the expected accumulation of citrate. Holz (1954), however, was able to show 
accumulation of large amounts of citrate in fluoroacetate-poisoned Euglena of the same strain. Thus, it seems that the mechanism of fluoroacetate inhibition in Euglena is the same as that in the tissues of higher animals.

Figure 1 shows that $0.001 \mathrm{~m}$-fluoroacetate inhibited endogenous oxygen consumption of Euglena by about $68 \%$. Further increases in concentration did not result in appreciably greater inhibition. It seems likely, therefore, that the endogenous metabolism occurs, in large part at least, through pathways in which citrate is an intermediate.

The respiratory quotient of the endogenous metabolism. Determination of the respiratory quotient of the endogenous metabolism also yielded some information concerning the nature of the substrates involved, though such data cannot provide positive identification of the substrates. Six experiments, using cells grown on acetate + Tryptone at $\mathrm{pH} 7 \cdot 3$ and ethanol + Tryptone at $\mathrm{pH} \mathrm{3.5}$, resulted in an average respiratory quotient of $1 \cdot 05 \pm 0 \cdot 19$. The respiratory quotient of the endogenous, like its rate, was independent of the $\mathrm{pH}$ value and substrate of growth, and of the composition and $\mathrm{pH}$ value of the experimental media.

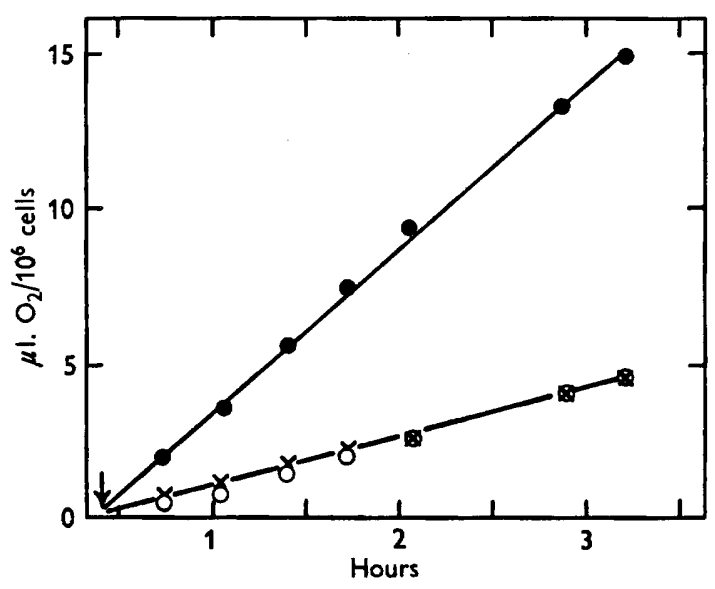

Fig. 1. Effect of fluoroacetate on the endogenous oxygen consumption by Euglena. Warburg flasks contained 17.4 million Euglenas in $8.0 \mathrm{ml} .0 .01 \mathrm{M}$-phosphate buffer(pH7.0). Temperature was $26^{\circ}$. Time is measured from the time of addition of fluoroacetate; the arrow indicates the time manometer readings were begun. $\theta$, No fluoroacetate; $x$, 0.001 M-fluoroacetate : $0,0.04$ m-fluoroacetate.

The respiratory quotient of approximately 1.0 suggests that the endogenous store is carbohydrate in nature.

Interaction of endogenous and exogenous metabolism. Wilson \& Danforth (1958) concluded, on the basis of respirometric data, that the endogenous metabolism of Euglena continues unchanged during the oxidation of exogenous acetate. This conclusion was based on indirect evidence; it was assumed that the ratio of acetate oxidized to acetate assimilated in short-term experiments should be independent of the total amount of acetate utilized. It was found that the data fitted this assumption only when corrected for a continuing endogenous metabolism. In the case of ethanol, this criterion did not permit a decision as to whether or not the endogenous metabolism continued. 
Blumenthal, Koffler \& Heath (1957) showed that the manometric method described above and measurements based on release of radioactive carbon dioxide from ${ }^{14} \mathrm{C}$-labelled cells may lead to apparently contradictory conclusions concerning the effect of exogenous substrates on endogenous metabolism. It seemed desirable, therefore, to compare results obtained by the tracer method with our earlier respirometric studies. Figures 2 and 3 show the results of two such experiments, in which Euglena which had assimilated small amounts of radioactive acetate were then incubated in the presence and in the absence of exogenous substrate.

In the absence of substrate, the rate of ${ }^{14} \mathrm{CO}_{2}$ production decreases rapidly with time; the decrease follows an approximately logarithmic time-course. This decrease cannot be attributed solely to the decreasing radioactivity of the cells, since at the

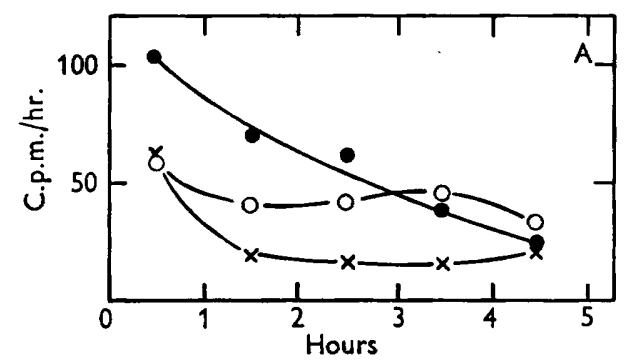

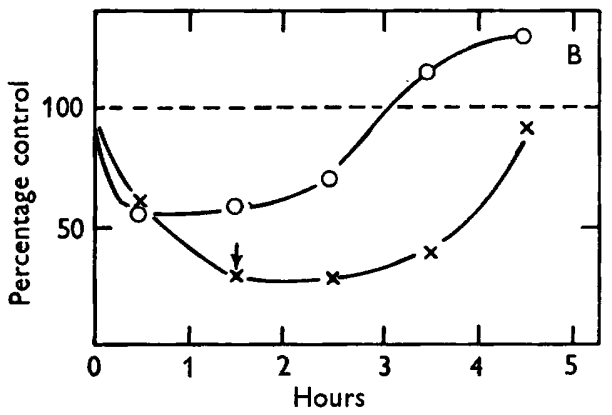

Fig. 2
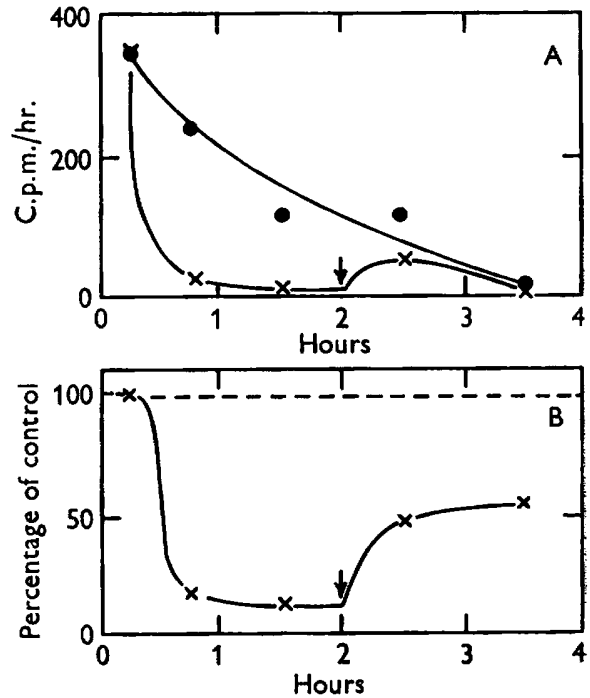

Fig. 3

Fig. 2. Effect of nonradioactive substrate on release of ${ }^{14} \mathrm{CO}_{2}$ by 'partially labelled' Euglena. $\mathrm{CO}_{2}$ trapped by first method (see 'Methods'). Incubation mixtures contained per flask, 15.3 million Euglenas, 1450 c.p.m., in $1.0 \mathrm{ml}$. $0.03 \mathrm{M}$-phosphate buffer (pH 7.0). Temperature was $25-27^{\circ}$. A, Rates of ${ }^{14} \mathrm{CO}_{2}$ release. The average rate of release is plotted in the mid-point of the measuring interval. $\mathrm{B}$, Rates of ${ }^{14} \mathrm{CO}_{2}$ release as $\%$ rate in the absence of substrate. No substrate; $x, 20 \mu$ mole acetate; $0,20 \mu$ mole ethanol. Arrow indicates the most probable time of acetate exhaustion.

Fig. 3. Effect of non-radioactive acetate on release of ${ }^{14} \mathrm{CO}_{2}$ by 'partially labelled' Euglena. $\mathrm{CO}_{2}$ trapped by second method. Incubation mixtures contained per flask, 2.0 million Euglenas in $1.5 \mathrm{ml}$. $0.008 \mathrm{M}$-phosphate buffer, $\mathrm{pH} \mathrm{7.0}$. Temperature was $26^{\circ}$. $A$ and B, Data plotted as in Figs. 2A and 2B, respectively. Arrow indicates time of removal from acetate. - No substrate; $\times, 20 \mu$ mole acetate $/ \mathrm{ml}$.

end of the experiment shown in Fig. 2, the cells retained more than $90 \%$ of their original radioactivity, while the rate of release of the ${ }^{14} \mathrm{CO}_{2}$ had dropped to about $25 \%$ of the initial rate.

It is apparent that the presence of exogenous acetate or ethanol markedly reduces the rate of ${ }^{14} \mathrm{CO}_{2}$ production by labelled cells. The course of this 'inhibition' is 
clearest when the data are plotted as in Figs. $2 \mathrm{~B}$ and $3 \mathrm{~B}$, expressing the rates of ${ }^{14} \mathrm{CO}_{2}$ production in the presence of substrate as percentage of the endogenous rates over the same time intervals. The inhibition develops gradually after addition of the substrate; in the experiment shown in Fig. 3, there was no inhibition during the first half hour after addition of acetate. With time, the rate of ${ }^{14} \mathrm{CO}_{2}$ release recovers toward or beyond the endogenous rate. It seemed probable that the recovery began at the time when the exogenous substrate was exhausted. In the experiment shown in Fig. 2, the probable time of exhaustion of acetate was estimated from the amount of acetate added and the average rate of acetate utilization by Euglena cells in other experiments performed under the same conditions. The vertical arrow in the figure indicates the most probable time of acetate exhaustion. In the experiment shown in Fig. 3, the known time of transfer from acetatecontaining to endogenous medium is shown by a similar arrow.

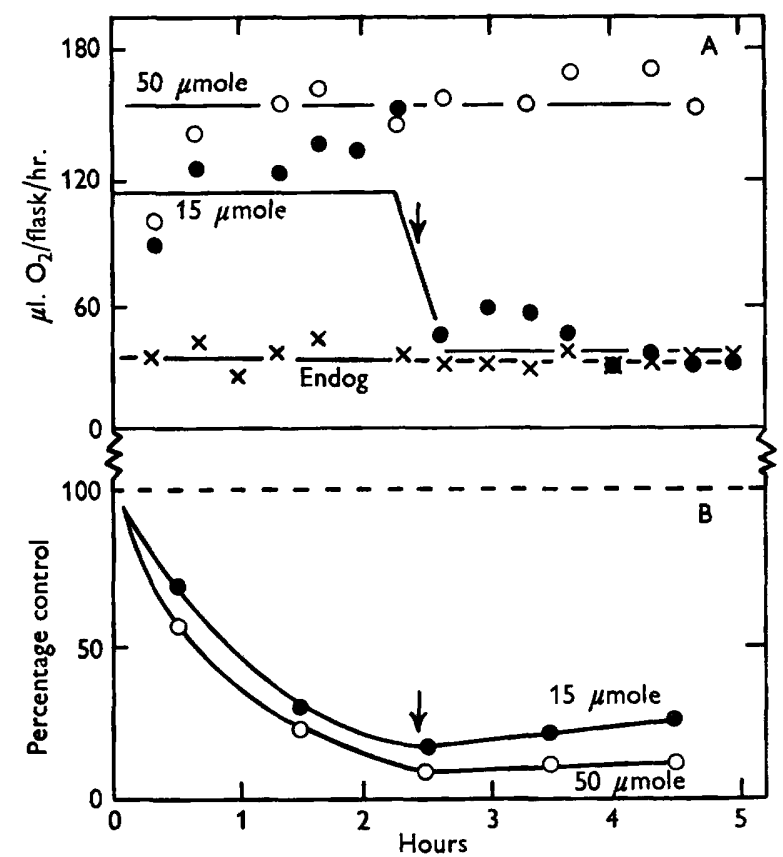

Fig. 4. Effect of nonradioactive acetate on respiration and rate of release of ${ }^{14} \mathrm{CO}_{2}$ by 'partially labelled' Euglenas. $\mathrm{CO}_{2}$ trapped by first method. Mixtures contained per flask, 6.0 million Euglenas, 4750 c.p.m., in $1.0 \mathrm{ml}$. 0.008 $\mathrm{M}$-phosphate buffer, pH 7.0. Temperature was $24^{\circ}$. A, Rates of oxygen consumption. B, Rates of ${ }^{14} \mathrm{CO}_{2}$ release as $\%$ of rate with no substrate. Figures beside the curves indicate the amounts of acetate added.

It is clear that the decreased rate of ${ }^{14} \mathrm{CO}_{2}$ production persists for as long as several hours after depletion of exogenous substrate. This fact is apparent in Fig. 4, which records an experiment in which rates of oxygen consumption and ${ }^{14} \mathrm{CO}_{2}$ production were measured simultaneously in duplicate flasks. Since the respiratory quotient of both endogenous and acetate (Wilson \& Danforth, 1958) is 1:0, the total (labelled plus unlabelled) $\mathrm{CO}_{2}$ production may be taken as equal to the oxygen consumption. Two initial values of acetate, 15 and $50 \mu$ mole, were used. The former was exhausted during the course of the experiment, while the latter was not. As before, the inhibi- 
tion of radioactive $\mathrm{CO}_{2}$ production developed gradually and persisted for several hours after the sharp drop in respiratory rate to the endogenous value, which indicates exhaustion of the acetate.

Blumenthal et al. (1957) also showed that the apparent effect of exogenous substrates on endogenous metabolism might vary, depending on whether the cells were labelled by brief exposure to radioactive substrate or were grown from a small inoculum entirely on uniformly labelled substrate. In the first case, various endogenous substrates may be labelled to different degrees, while in the second all cellular constituents are uniformly radioactive. For this reason, experiments were performed on Euglena grown through several-hundredfold multiplication on radioactive acetate. Such cells were not strictly 'uniformly-labelled', since the acetate
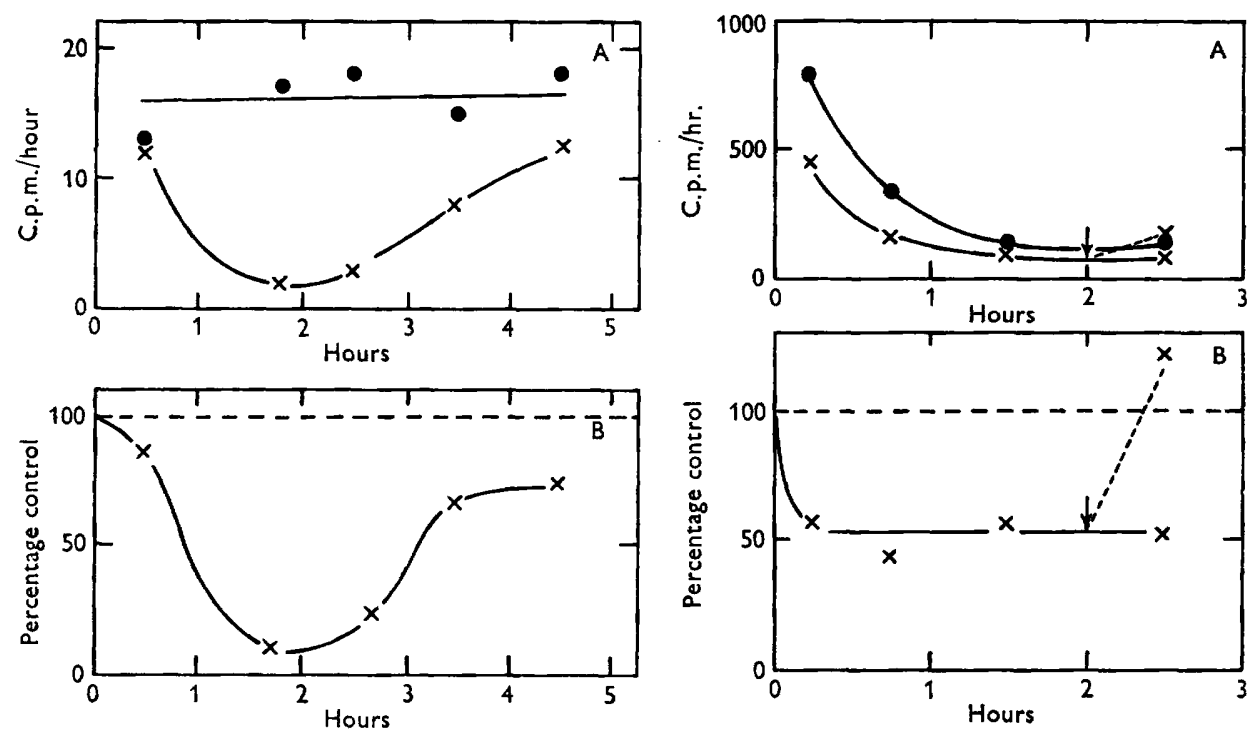

Fig. 5

Fig. 6

Fig. 5. Effect of non-radioactive acetate on release of ${ }^{14} \mathrm{CO}_{2}$ by 'fully labelled' Euglena. $\mathrm{CO}_{2}$ trapped by first method. Incubation mixtures contained per flask, 6.8 million Euglenas, 4380 c.p.m., in $1.0 \mathrm{ml} .0 .008 \mathrm{M}$-phosphate buffer, $\mathrm{pH} \mathrm{7.0.} \mathrm{Temperature} \mathrm{was} 21^{\circ}$. A and B, Data plotted as in Fig. $2 \mathrm{~A}$ and $2 \mathrm{~B}$ respectively. $\odot$, No substrate; $x, 10 \mu$ mole acetate.

Fig. 6. Effect of non-radioactive acetate on release of ${ }^{14} \mathrm{CO}_{2}$ by 'partially labelled' Et-grown Euglena. $\mathrm{CO}_{2}$ trapped by second method. Incubation mixtures contained per flask, 18.5 million Euglenas in $1.5 \mathrm{ml}$. 0.008 $\mathrm{m}$-phosphate buffer (pH 7.0). Temperature was $26^{\circ}$. At the time indicated by the arrow, one sample of cells was transferred from acetate medium to endogenous medium (dotted curve). A and B, Data plotted as in Fig. $2 \mathrm{~A}$ and $2 \mathrm{~B}$, respectively. $\bullet$, No substrate; $\times, 20 \mu$ mole acetate $/ \mathrm{ml}$.

used for growth was labelled only in the methyl carbon, and since the nonradioactive Bacto-Tryptone in the medium probably supplied some carbon to the cells. But such cells certainly more closely approach uniformity of labelling than do those used in the preceding experiments.

Figure 5 shows the results of an experiment with such 'fully-labelled' cells. A comparison with Figs. 2 and 5 shows a number of interesting differences. Although the initial radioactivity of the 'fully-labelled' cells was about twice that of the 
partially labelled, the rate of release of ${ }^{14} \mathrm{CO}_{2}$ was much lower in the fully labelled. This would be expected if newly assimilated acetate is converted mainly into the cellular constituents most readily available as endogenous substrates. This explanation is supported by the fact that the rate of production of radioactive $\mathrm{CO}_{2}$ by partially labelled cells decreases rapidly with time, while that of the fully labelled cells remains constant over the same period of time.

The effect of exogenous acetate on the release of radioactive $\mathrm{CO}_{2}$ is, however, the same in fully-labelled cells as in partially labelled. There is the same gradual decrease in rate to about $10-30 \%$ of the endogenous rate, and the same slow recovery following disappearance of the exogenous acetate.

All of the preceding experiments were done on Euglena which had been grown

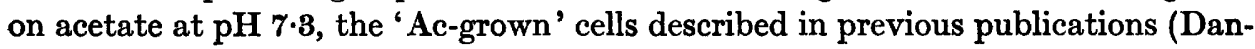
forth \& Wilson, 1957; Wilson \& Danforth, 1958). Cells grown on ethanol at pH 3.5 ('Et-grown') have much lower rates of acetate metabolism. We were interested, therefore, in comparing the effect of acetate on endogenous metabolism in Et-grown cells with that in Ac-grown cells. Figure 6 shows the results of an experiment similar to that of Fig. 3, but performed with Et-grown Euglena. Two differences are apparent; with Et-grown cells the inhibition develops more rapidly, but the final level of inhibition is less than with Ac-grown cells.

The volume of Euglena cells. The volume of Euglena cells was estimated from a series of twenty-three determinations on four different cell suspensions. The averages for the four suspensions ranged from 1.15 to $1.80 \mu \mathrm{l}$./million cells, with a grand average of $1.58 \mu \mathrm{l} . \pm 0.12 \mu \mathrm{l}$./million cells. This volume is about half that found by Neff (1960) for a green strain of Euglena gracilis var. bacillaris. Strain differences or differences in culture methods may account for this discrepancy.

\section{DISCUSSION}

Effect of substrates on the endogenous metabolism. The utilization of exogenous acetate or ethanol greatly depresses the rate of release of radioactive $\mathrm{CO}_{2}$ by Euglena previously labelled with radioactive carbon. At first glance, these results seem to indicate that, contrary to our earlier conclusions, the presence of exogenous substrate depresses the rate of endogenous $\mathrm{CO}_{2}$ production. Two facts, however, suggest that the situation is not quite so simple. First, the rate of release of radioactive $\mathrm{CO}_{2}$ remains depressed for more than an hour after the substrate has been exhausted. But numerous manometric experiments have shown that, after acetate exhaustion, the respiratory rate returns promptly to the endogenous level, as illustrated in Fig. 4. Secondly, it would be difficult to explain the gradual onset of the inhibition of ${ }^{14} \mathrm{CO}_{2}$ production by any mechanism involving a direct competition between the endogenous and acetate metabolism, since acetate metabolism begins at maximum rate almost immediately upon the addition of acetate. On the other hand both the gradual onset of the inhibition and the persistence of the inhibition after acetate exhaustion can be explained if it is assumed that the rate of total $\mathrm{CO}_{2}$ production from endogenous sources remains unchanged in the presence of acetate, but that the specific radioactivity of the endogenous reserves is lowered by the assimilation of non-radioactive substrate, thus decreasing the radioactivity of the $\mathrm{CO}_{2}$ produced from this source. 
A metabolic scheme in which such dilution might occur is shown in Fig. 7. In this model, it is assumed that the endogenous reserves are composed of two (or more) components, a 'labile reserve' which is the immediate source of substrate for endogenous metabolism, and a larger pool of 'stable reserve(s)' from which the labile reserve is replenished. It is further assumed that endogenous acetate or ethanol is assimilated directly into the labile reserve, and enters the stable reserve only indirectly. Such a model explains the fact, noted previously, that the most recently-assimilated reserves are most readily available for endogenous metabolism. The decrease with time of the rate of endogenous ${ }^{14} \mathrm{CO}_{2}$ production by partially labelled cells would occur not only because of rapid re-oxidation of the new, radioactive reserves, but also because of the exchange of material between highly radioactive labile reserve and the less active stable reserve.

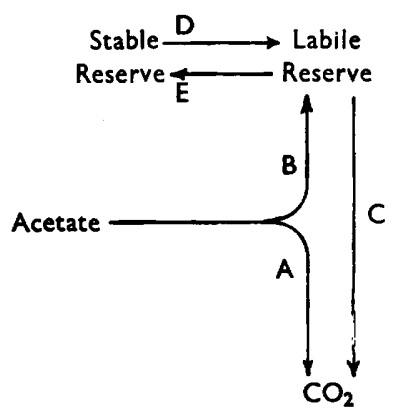

Fig. 7. Hypothetical model of acetate and endogenous metabolism in Euglena.

In this model, then, reaction $\mathbf{C}$ is the continuing endogenous metabolism of Wilson \& Danforth (1958), reaction A the oxidation of exogenous acetate, and reaction $B$ the assimilation of acetate. When unlabelled acetate is present, the assimilation of non-radioactive carbon directly into the labile reserve would dilute these reserves, lowering the specific activity of the $\mathrm{CO}_{2}$ produced via reaction $\mathrm{C}$, even though the total rate of $\mathrm{CO}_{2}$ production from this pathway remained unchanged. The extent of dilution would increase with time, and the dilution would persist for a time after the exhaustion of substrate, in agreement with the experimental findings.

This model also accounts for the fact that 'inhibition' of ${ }^{14} \mathrm{CO}_{2}$ production by acetate is less in Et-grown than in Ac-grown cells, since both reaction $\mathbf{A}$ and reaction $\mathbf{B}$ (oxidation and assimilation of acetate) are slower in Et-grown cells. The labile reserves would therefore be less diluted by acetate in the case of Et-grown cells. The precise mechanism of the more rapid onset of inhibition in Et-grown cells is not known, but the phenomenon is not inconsistent with the model presented here.

The only essential feature of the model presented is the assumption that the newly-assimilated material 'pools' more rapidly with the immediate substrate of endogenous metabolism than with the remainder of the endogenous reserves. In other respects, the model is probably oversimplified. In particular, it seems doubtful that only two compartments are involved, and that the distinction between labile and stable reserves is a sharp one. A series of many compartments with varying degrees of 'lability' would probably be closer to reality. 
Nature of the endogenous reserves. While the present experiments do not permit conclusive identification of the nature of the endogenous reserves, they provide a number of important clues. For example, from the rate and duration of endogenous respiration, it was calculated that the reserves contain at least the equivalent of about $I \mu$ mole of hexose per million cells. From the measured volume of the cells, this would amount to the equivalent of an approximately $0.6 \mathrm{M}$-hexose solution, a concentration larger than any reasonable estimate of the total osmolar concentration of Euglena cytoplasm. Thus, the bulk of the reserves must be in the form of high molecular weight compounds, or of insoluble materials.

The respiratory quotient of 1.0 suggests that the endogenous reserves are carbohydrate in nature. Paramylum, a polymer of $\mathrm{D}$-glucose, is a likely candidate for the stable reserve substance. It is present in Euglena as granules which are frequently so numerous as to be the most conspicuous cellular inclusions. These granules have been observed to decrease in size and number during prolonged starvation (Gojdics, 1953; Padilla \& Buetow, 1959).

Pathroay of endogenous metabolism. The effectiveness of fluoroacetate as an inhibitor of endogenous respiration suggests that the endogenous metabolism occurs via the Krebs tricarboxylic acid cycle. Since acetate is also probably oxidized through the Krebs cycle (Danforth, 1953), the apparent lack of competition between acetate metabolism and endogenous metabolism is puzzling. The present experiments provide no information concerning the mechanism which permits the two processes to go on side by side without interference. Approximately $33 \%$ of the endogenous oxygen uptake is insensitive to fluoroacetate inhibition. This is roughly the amount of oxygen which would be required for the partial oxidation of carbohydrate to the level of acetate, the point at which the fluoroacetate block occurs.

Role of the endogenous metabolism. The constancy of the endogenous metabolism in the face of varying conditions, and its persistence during oxidation of exogenous nutrients, suggest that the endogenous pathways play a special role in Euglena metabolism which goes beyond merely providing a reserve of carbon and energy. It is worth noting, in this connexion, that Euglena gracilis will grow at maximum rates in the presence of substances which do not stimulate respiration appreciably above the endogenous level (Wilson, Buetow, Jahn \& Levedahl, 1959). Thus, the rate of endogenous metabolism is sufficient to supply all the energy needed by growing cells. It is possible, therefore, that the endogenous metabolism is the direct source of energy for growth, movement, osmotic regulation, and other 'life processes', and that exogenous substrates are used only to replenish or increase the supply of endogenous reserves.

These investigations were aided by grants from the American Cancer Society and the National Science Foundation.

\section{REFERENCES}

Blumenthat, H. J., Koffler, H. \& Heath, J. (1957). Biochemistry of filamentous fungi. V. Endogenous respiration during concurrent metabolism of exogenous substrates. J. cell. comp. Physiol. 50, 471.

Cramer, M. \& Myers, J. (1952). Growth and photosynthetic characteristics of Euglena gracilis. Arch. Mikrobiol. 17, 384. 
Dach, H. Von (1942). Respiration of a colorless flagellate, Astasia klebsii. Biol. Bull., Wood's Hole, 82, 356.

Danforth, W. F. (1952). Oxidative Metabolism of Euglena. Doctoral dissertation, University of California, Los Angeles, California, U.S.A.

Danforth, W. (1953). Oxidative metabolism of Euglena. Arch. Biochem. Biophys. 46, 164.

Danforth, W. F. \& Wilson, B. W. (1957). Adaptive changes in the oxidative metabolism of Euglena. J. Protozool. 4, 52.

GoJdics, M. (1958). The Genus Euglena, p. 24. The University of Wisconsin Press. Madison, Wisconsin.

Houz, G. G. (1954). The oxidative metabolism of a cryptomonad flagellate, Chilomonas paramecium. J. Protozool. $1,114$.

NeFF, R. H. (1960). Volume, nucleic acid and nitrogen contents of strains of green and colorless Euglena gracilis and of Astasia longa. J. Protozool. 7, 69.

Padilla, G. M. \& Buetow, D. E. (1959). Effects of starvation on the streptomycinbleached flagellate, Euglena gracilis var. bacillaris. J. Protozool. 6 (Suppl.), 29.

Petrers, R. A. (1952). Lethal synthesis. Proc. Roy. Soc. B, 139, 143.

Peters, R. A. (1957). Mechanism of the toxicity of the active constituent of Dichapetalum cymosum and related compounds. Advanc. Enzymol. 18, 113.

Wilson, B. W., Buetow, D. E., Jahn, T. L. \& Levedahl, B. H. (1959). A differential effect of pH on cell growth and respiration. Exp. cell Res. 18, 454.

WILSON, B. W. \& DANFORTH, W. F. (1958). The extent of acetate and ethanol oxidation by Euglena gracilis. J. gen. Microbiol. 18, 535. 